\title{
COOPERACIÓN INTERNACIONAL EN MATERIA PENAL EN EL MERCOSUR: EL CIBERCRIMEN
}

\section{COOPERAÇ̃̃O INTERNACIONAL EM MATÉRIA PENAL NO MERCOSUL: O CIBERCRIME}

\author{
Santiago Deluca ${ }^{*}$ \\ Enrique del Carril ${ }^{* *}$
}

Resumen: En el MERCOSUR no existe un derecho penal común, no obstante observarse una creciente corriente orientada a la adopción de normas generales de política criminal tendiente a combatir diversos actos delictivos. Ello se cristaliza en la creación de normas de cooperación internacional en materia penal, con el objeto de lograr la asimilación y adecuación "macro" de las legislaciones penales de los Estados Parte.

Es justo reconocer que en este trabajo no se pretende elaborar un corpus iuris por simple traslación de conceptos o legislación mercosureña, todo lo contrario. Por medio del análisis de las particularidades jurídicas del proceso de integración y sus instrumentos de derecho se busca dejar sentado que el MERCOSUR se encuentra encaminado en la creación de un espacio integrado de cooperación en materia penal, más allá del aspecto pura y exclusivamente económico. Y, principalmente, analizar cómo se presenta hoy en día la modalidad conocida como cibercrimen y la utilidad de las herramientas señaladas para lograr combatirlo.

Resumo: Não existe um direito penal comum no MERCOSUL, apesar disso se pode observar uma tendência crescente para a adoção de regras gerais de política criminal destinadas a combater vários atos criminosos. Isso se cristaliza na criação de normas de cooperação internacional em matéria penal, com o objetivo de alcançar a assimilação e a adaptação "macro" das leis penais dos Estados Parte.

É justo reconhecer que este artigo não pretende elaborar um corpus iuris por simples tradução de conceitos ou legislação do MERCOSUL, muito pelo contrário. Através de uma análise das peculiaridades legais do processo de integração e dos seus instrumentos jurídicos, procura-se estabelecer que

* Asociación de Estudios de Integración -AdEI, Argentina.

** Ministerio Público Fiscal de Buenos Aires, Argentina.

E-mail: delucasantiago@hotmail.com

Recibido: 08/09/2017. Aceptado: 10/10/2017. 
o MERCOSUL se destina a criar um espaço integrado de cooperação em questões criminosas, além de suas particularidades puramente econômicos. $E$, principalmente, analisar como é apresentadao hoje a modalidade conhecida como cibercrime e a utilidade das ferramentas indicadas para combatê-lo.

Palabras clave: Cibercrimen, Cooperación penal, Traslado de condenados, Extradición, MERCOSUR, Derecho de la integración

Palavras-chave: Cibercrime, Cooperação penal, Transferência de pessoas condenadas, Extradição, MERCOSUL, Direito da integração

\section{ASPECTOS PRELIMINARES: EL DERECHO DEL MERCOSUR}

Ya se ha dicho ${ }^{1}$ que el núcleo central -constitutivo- de las fuentes del derecho o fuente primaria nos ubica frente al Tratado de Asunción ${ }^{2}$ y sus Protocolos Adicionales.

Esta normativa originaria es de carácter jurídico-internacional. Se fundamenta en el consentimiento estatal, formado a través de los procedimientos constitucionales de cada uno de los Estados Parte ${ }^{3}$. Y, a su vez, por tratarse de normas convencionales internacionales sujetas a las reglas del derecho internacional en materia de tratados -es decir a la Convención de Viena sobre Derecho de los Tratados ${ }^{4}$ - se instrumentan a través del sistema jurídico internacional previsto para los Tratados celebrados en forma solemne.

Junto a los instrumentos jurídicos mencionados, pero en una escala jerárquica inferior, encontramos las fuentes derivadas, conformadas por los actos adoptados por los órganos del MERCOSUR para la aplicación o ejecución de los principios y objetivos establecidos por dicho Tratado y Protocolos.

En este contexto y a los efectos de permitir el correcto desarrollo del proceso de integración, el Protocolo de Ouro Preto ${ }^{5}$ enumera taxativamente las fuentes jurídicas del MERCOSUR, fija una prelación

\footnotetext{
1 DELUCA, Santiago. "El MERCOSUR tras la suspensión de Paraguay y el ingreso de Venezuela: ponderación del Laudo TPR No1/2012". Papeles de Derecho Europeo e Integración Regional. 2013, no 16.

2 Suscripto el 26 de marzo de 1991 dando inicio al proceso de integración mercosureño. En adelante TA.

3 Profundizar en PEROTTI, Alejandro. Habilitación constitucional para la integración comunitaria. sl: Fundación Konrad Adenauer, 2004.

Asimismo, se recomienda la lectura de KLEIN VIEIRA, Luciane. "La reforma de las constituciones de los Estados Partes del MERCOSUR”. En LL. 25 de julio de 2012, p. 4-7.

4 Suscripta el del 23 de mayo de 1969. Sobre el tema MANGAS MARTÍN, Araceli, LIÑÁN NOGUERAS, Diego J. Instituciones y derecho de la Unión Europea. $2^{\mathrm{a}}$ ed. sl: McGraw-Hill, 1999; FLOREAL GONZÁLEZ, Flavio. "MERCOSUR: un orden jurídico debilitado y dispar. La necesidad de un cambio". En $L L$, año 54, n 61, p. 2.

5 Firmado el 17 de diciembre de 1994. En adelante POP.
} 
normativa y establece un orden ${ }^{6}$. Es decir, una imposición racional entre las normas que lo integran y una relación de subordinación y jerarquía ${ }^{7}$, clasificándolas en tres grupos diferentes ${ }^{8}$.

Además de estos instrumentos jurídicos convencionales encontramos otra categoría constituida por el conjunto de normas aplicables en el ordenamiento jurídico del MERCOSUR -incluso no escritas- que se traducen en actos atípicos o sui géneris, como los principios generales del derecho o la jurisprudencia, o cuyo origen es exterior al ordenamiento jurídico del bloque, como el derecho surgido de las relaciones exteriores o el derecho complementario emanado de los actos convencionales celebrados entre los Estados Parte para la aplicación del TA?

\section{LA COOPERACIÓN INTERNACIONAL EN MATERIA PENAL EN EL MERCOSUR}

La cooperación en materia judicial penal se traduce en acuerdos entre Estados surgidos de la necesidad de comunicarse, ya sea para procurarse pruebas e información, o bien para pedirse y obtener la entrega de individuos ubicados fuera de sus territorios para someterlos a proceso o cumplimiento de una condena.

Los tribunales nacionales aceptan la participación de órganos jurisdiccionales de otros Estados, o requieren o excitan esa participación cuando lo estiman conveniente a los fines del proceso penal instaurado en su propia jurisdicción. Ello implica -en definitiva- la comunicación para obtener medios de prueba e información y la comunicación de personas acusadas o condenadas ${ }^{10}$.

Si se hace un rápido repaso de las decisiones emanadas del Consejo Mercado Común ${ }^{11}$ desde el año $1991^{12}$ a la fecha, podrán encontrarse sendas y variadas normas que abarcan la más diversa índole. Lo mismo ocurre con los pronunciamientos de los Jefes de Estado, que reflejan en forma fiel los objetivos perseguidos por quienes se encuentran en cada momento a cargo de la conducción del MERCOSUR en oportunidad de

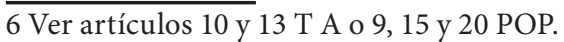

7 SAN MARTINO DE DROMI, María Laura. De la nueva historia del Derecho. A propósito del objeto, método y fuentes del Derecho del MERCOSUR. Buenos Aires: Ciudad Argentina, 1997, p. 100.

8 JARDEL, Silvina; BARRAZA, A. MERCOSUR: aspectos jurídicos y económicos. Buenos Aires: Ciudad Argentina, 1998, p. 83-85. Resultan interesantes los planteos y cuestionamientos que efectúan los autores respecto de la implicancia y finalidad de la enumeración que lleva a cabo el artículo 41 POP.

9 DELUCA, Santiago. Unión Europea y MERCOSUR: los efectos del derecho comunitario sobre las legislaciones nacionales. Buenos Aires: Rubinzal-Culzoni Editores, 2003, Cap. II.

10 DIBUR, José Nicasio; DELUCA, Santiago. Extradiciones: tratados y convenios. Buenos Aires: Editorial Ad Hoc, 2006.

11 En adelante CMC.

1226 de marzo de 1991, fecha de suscripción del Tratado de Asunción, constitutivo del Mercado Común del Sur. 
ejercer la Presidencia Pro Témpore ${ }^{13}$.

Particularmente, en lo que atañe al tema que nos incumbe, pueden mencionarse entre tantas otras: CMC/Dec. No 06/92 Recomendación a los gobiernos de los Estados Parte para la ratificación de la convención interamericana sobre restitución internacional de menores; CMC/Dec. No 2/96 Protocolo de asistencia jurídica mutua en asuntos penales; $\mathrm{CMC} / \mathrm{Dec} \mathrm{N}^{\circ}$ 5/98 Plan de cooperación y asistencia recíproca para la seguridad regional en el MERCOSUR; CMC/Dec. No 14 y N $^{\circ}$ 15/98 Acuerdo sobre extradición entre los Estados Parte del MERCOSUR, Bolivia y Chile; CMC/Dec. N 16/99 y 17/99 Acuerdo de Asunción sobre restitución de vehículos automotores terrestres y/o embarcaciones que trasponen ilegalmente las fronteras entre los Estados Parte del MERCOSUR, Bolivia y Chile; CMC/Dec. No 22/99 Plan general de cooperación y coordinación reciproca para la seguridad regional; CMC/Dec. No 3/01 Programa de acción del MERCOSUR al combate de los ilícitos en el comercio internacional; CMC/Dec. No 34 y $\mathrm{N}^{\circ} 35 / 04$ Proyectos de acuerdo sobre traslado de personas condenadas entre los Estados Parte del MERCOSUR y entre los Estados Parte del MERCOSUR y la república de Bolivia y la república de Chile; CMC/ Dec. No 36/04 Sistema de intercambio de información de seguridad del MERCOSUR (SISME); CMC/Dec N 37/04 Proyecto de acuerdos contra el tráfico ilícito de migrantes, entre los Estados Parte del MERCOSUR, la república de Bolivia y la república de Chile; CMC/Dec. $\mathrm{N}^{\circ}$ 17/05 Protocolo de Asunción sobre compromiso con la promoción y protección de los derechos humanos del MERCOSUR; CMC/Dec. $\mathrm{N}^{\circ}$ 13/05; Protocolo sobre el traslado de personas sujetas a regímenes especiales; CMC/Dec. N $\mathrm{N}^{\circ}$ 16/06 Acuerdo marco sobre cooperación en materia de seguridad regional entre los Estados Parte del MERCOSUR y la república de Bolivia, la república de Chile, la República de Ecuador, la República de Perú y la República Bolivariana de Venezuela; CMC/ Dec. $\mathrm{N}^{\circ}$ 48/10 Acuerdo sobre la orden MERCOSUR de detención y procedimientos de entrega entre los Estados Parte del MERCOSUR y Estados Asociados.

A la luz del vasto plexo normativo reseñado, si se parte de la consideración inequívoca de que el MERCOSUR, como todo proceso de integración que se precie de tal reconoce un claro e indiscutible origen económico comercial ${ }^{14}$, más allá de que la elaboración de una teoría que

$13 \mathrm{Al}$ respecto, es dable aclarar que tales pronunciamientos no revisten interés mayor que desde el punto de vista político.

14 En efecto, ha de señalarse que el fundamento jurídico internacional del MERCOSUR, que le permite desarrollarse como tal y lo exceptúa de extender los mayores beneficios que se otorgan los Estados Parte a otros países latinoamericanos e incluso de otras latitudes pero que también forman parte de la Organización Mundial de Comercio, es la inscripción del Tratado de Asunción de 26 de marzo de 1991 como un Acuerdo de Alcance Parcial de Complementación Económica -el ACE N¹8- al amparo del Tratado de Montevideo de 1980 constitutivo de ALADI. Proceso de integración latinoamericano que -a su vez- permite la 
sostenga la existencia de dos pilares complementarios al económico supera los objetivos fijados para este trabajo ${ }^{15}$, puede afirmarse la coexistencia de estos dos pilares complementarios. Más concretamente, uno atinente a Política Exterior y Seguridad Común y otro a Interior y Justicia ${ }^{16}$.

Centraremos nuestro análisis en el último de estos "pilares".

\section{EL PROTOCOLO DE SAN LUIS DE 1996}

El Protocolo de Asistencia Jurídica Mutua en Materia Penal ${ }^{17}$ reconoce en sus considerandos que la cooperación en materia jurídica contribuye a profundizar la reciprocidad de intereses de los Estados Parte en el proceso de integración y que la respuesta colectiva es necesaria por la grave amenaza que se manifiesta a través de modalidades criminales transnacionales.

Su objeto radica en regular la cooperación en materia de recepción y producción de prueba (documentos, testimonios, peritajes, registros, etc.), los procedimientos particulares para la localización de personas, el traslado de las personas sujetas a proceso penal, las medidas cautelares sobre bienes, la emisión yla ejecución de órdenes de captura o de citaciones, la incautación, transferencia de bienes decomisados y otras medidas de naturaleza similar, aseguramiento de bienes a efectos del cumplimiento de sentencias judiciales que impongan indemnizaciones multas, etc. ${ }^{18}$.

Es decir, se prevé una amplia gama de actividades a desarrollarse en el ámbito del Estado requerido que de otra forma no sería posible llevar a cabo, ya que se violaría la actividad jurisdiccional por él desplegada. En cuyo caso, de no contarse con esta herramienta de cooperación, se verificaría una serie de consecuencias negativas en los Estados requirentes que obstaculizarían el buen funcionamiento de su aparato judicial.

Por su parte, no obstante la facultad discrecional que se otorga a los Estados para solicitar la asistencia en materia penal a otro Estado parte del MERCOSUR, se prevé que los Estados pueden rechazar la prestación de asistencia si el requerimiento se refiere a un delito militar,

formación de procesos de integración sub regionales en razón de su inscripción al amparo de la Cláusula de Habilitación aprobada en el marco de la Ronda de Tokio del GATT de 1979, que posibilita a los Estado en vía de desarrollo formar este tipo de asociaciones aun cuando no cumplan con los requisitos del art. XXIV del GATT, excepcionándose de aplicar el principio de no discriminación en sus dos variantes de trato nacional y nación más favorecida, establecido en el artículo I del GATT.

15 Tal como se sucedió en la UE a partir del Tratado de Maastricht de 1991 y hasta la entrada en vigencia el 1 de enero de 2009 del Tratado de Lisboa.

16 Sobre el particular se recomienda ampliar en DELUCA, Santiago. "El MERCOSUR necesita su Maastricht". Revista Pensar en Derecho. 2012. no 1. DELUCA, Santiago. "Es correcto hablar de un derecho penal del MERCOSUR?". En Derecho Penal Empresario. Buenos Aires: Editorial BdeF, 2010.

17 Suscripto en San Luis, Argentina, el 25 de junio de 1996, aprobado mediante CMC/Dec. $\mathrm{N}^{\circ} 2 / 96$ y con vigencia desde el año 2000.

18 Artículo 2. 
tributario o político, si la persona concernida ya fue juzgada por el mismo hecho en el país requerido o si el requerimiento atenta contra el orden público o contra los intereses esenciales del Estado requerido ${ }^{19}$.

En cuanto al procedimiento a seguir, se establece una autoridad de aplicación única en cada Estado que centraliza los requerimientos de asistencia y ésta actúa con base en los pedidos de asistencia de las autoridades judiciales o del Ministerio Público del Estado requirente encargados del juzgamiento o investigación de delitos ${ }^{20}$.

Al respecto cabe señalar que, si bien no resulta posible acceder a información específica relacionada a causas judiciales en trámite, desde el ámbito de la Procuración General de la Nación Argentina se ha puesto de manifiesto ya en 2007 que la totalidad de las solicitudes de asistencia y cooperación en materia penal cursadas por Estados miembros o asociados del MERCOSUR, son efectuadas sobre la base e invocación de los términos de este Protocolo ${ }^{21}$.

Dentro de las facultades otorgadas a los Estados requeridos, se destaca la vaguedad de los motivos por los cuales éstos pueden rechazar un pedido de asistencia concreto, así como el hecho de que las autoridades pueden postergar el cumplimiento de un pedido si, a su criterio, éste puede constituir un obstáculo a un proceso en curso ${ }^{22}$.

Por último, vale la pena poner de relieve que si bien especialistas en la materia se han expresado en favor de una cooperación judicial horizontal, que permitiría a los jueces y fiscales de los Estados Parte comunicarse directamente entre ellos con las ventajas que ello conlleva, en el Estado actual del proceso de integración ello no se observa como posible, principalmente y sin mencionar otros motivos, por el carácter intergubernamental que presenta el MERCOSUR ${ }^{23}$.

\section{EXTRADICIÓN EN EL MERCOSUR}

Puede decirse con parte de la doctrina que la extradición es "el acto por el cual un Estado entrega a un individuo a otro Estado que lo reclama, a objeto de someterlo a un juicio o a la ejecución de una pena"24, cuyo

19 Artículo 5.

20 Artículo 3 y 4.

21 Informe producido por la Procuración General de la Nación a solicitud de la Sub Comisión de Asuntos Penales de la Comisión del MERCOSUR de la Federación Argentina de Colegios de Abogados.

22 Artículo 9.

23 Intergubernamentalidad que surge del texto expreso del artículo 2 del Protocolo de Ouro Preto y que implica -ni más ni menos- la no delegación de competencias propias de los poderes públicos de los Estados hacia las instituciones u órganos del proceso de integración.

24 SOLER, Sebastián. Derecho Penal Argentino. Act. por Guillermo J. Fierro. Buenos Aires: Editorial TEA, 1992, tomo I, p. 235.

Asimismo, FIERRO, Guillermo J. "La ley penal y el derecho internacional" . 2a ed. Buenos Aires: Editorial Tea, 1997, p. 614-616. Los autores, en forma concordante, llevan a cabo un minucioso repaso de las diferentes acepciones del instituto de la extradición efectuadas por la 
objeto consiste en la entrega o traslado forzoso de una persona desde un territorio estatal a otro, fundado en la existencia de un tratado bilateral o multilateral, de una ley interna o de una convención internacional que imponen la obligación de extraditar, a causa de la presunta o cierta comisión anterior por parte de la persona requerida de una infracción punible cuyo juzgamiento o castigo es de competencia del Estado requirente ${ }^{25}$.

El instituto de la extradición fue incluido en el marco normativo del MERCOSUR a partir de la aprobación de las CMC/Dec. $\mathrm{N}^{\circ} 14 / 98$ y Nº15/98 ${ }^{26}$.

Como ya hemos dicho en anterior oportunidad ${ }^{27}$, ambas normas adoptan el sistema de cuantificación de la pena para la concesión de la extradición, previendo como límite que el delito sea punible en ambos Estados con una pena privativa de libertad cuyo máximo no sea inferior a dos años. Sin embargo, establecen que basta con que uno de los delitos cumpla con esta exigencia para que la extradición sea concedida por los demás ${ }^{28}$.

En lo que hace a la opción que se otorga al ciudadano del Estado requerido para ser juzgado o cumplir condena en el país, se establece el principio general de la no invocabilidad de la nacionalidad, excepto cuando exista una cláusula constitucional que en forma expresa impida la remisión de sus súbditos. No obstante, en estos casos la decisión de dar curso al extrañamiento quedará en manos del Estado requerido (cláusula facultativa $)^{29}$.

Esta acertada cláusula permitirá a los países que vean impedida la extradición de sus nacionales por imposición constitucional, sortear este impedimento incluyendo en su orden jurídico interno normas que, por su carácter comunitario ${ }^{30}$, admitirían hacer excepción a aquél principio constitucional, en virtud de las relaciones recíprocas que se crean entre las normas de uno y otro orden.

Por último, un dato curioso respecto de estas normas se presenta al analizar su aplicabilidad espacial, por cuanto prevén que el Acuerdo de extradición entrará en vigor, con relación a los dos primeros Estados

doctrina, tanto nacional como internacional.

25 Vid. FIERRO, Guillermo J. Op. cit., p. 616.

26 Ambas decisiones fueron firmadas en Río de Janeiro el 10 de diciembre de 1998 y regulan la extradición en el ámbito del MERCOSUR en forma idéntica. La primera entre los Estados Parte y la otra entre los Estados Parte, Bolivia y Chile.

27 Del CARRIL, Enrique; DELUCA, Santiago. "La Extradición en el Ámbito del MERCOSUR”. Sup. Dcho. Penal. 2003, vol 11.

28 Artículo 2.1 y 2.3 .

29 Artículo 11.1 y 11.2 .

30Si bien la cuestión de si el derecho del MERCOSUR es o no "derecho comunitario" resulta controvertida, consideramos que el derecho de la integración del MERCOSUR es un todo independiente diferente al derecho de los Estados Parte y en vías de consolidación, por lo cual no resulta correcto tratarlo como mera cooperación internacional aun cuando la cuestión terminológica pueda no ser la más exacta. Al respecto DELUCA, Santiago. Unión Europea y MERCOSUR: efectos del Derecho Comunitario en las legislaciones nacionales. Buenos Aires: Editorial Rubinzal Culzoni. 
Parte que lo ratifiquen, en un plazo de treinta días a contar de la fecha en que el segundo país deposite su instrumento de ratificación. Y, para los demás Estados Parte que lo ratifiquen, entrará en vigor el trigésimo día a partir del depósito de sus respectivos instrumentos de ratificación ${ }^{31}$.

La trascendencia de la metodología escogida para la aplicación de estas normas resulta del hecho de que contraría el sistema de vigencia simultáneo de las normas del MERCOSUR establecido por el Protocolo de Ouro Preto ${ }^{32}$, propio de todo esquema de integración de índole intergubernamental, habilitando a partir de entonces lo que se ha dado a conocer en el ámbito europeo como integración en distintas velocidades ${ }^{33}$.

Es decir que hoy en día estas decisiones tienen plena operatividad sólo respecto de Bolivia, Brasil, Chile, Ecuador, Paraguay y Uruguay que ya las han internalizado ${ }^{34}$. No así para Argentina, que continúa aplicando el régimen de la Ley 24767 o los tratados bilaterales o multilaterales que la vinculan con sus socios del MERCOSUR, impidiendo la armonización y unificación normativa sobre la materia.

\section{TRASLADO INTERNACIONAL DE CONDENADOS ENTRE LOS ESTADOS PARTE DEL MERCOSUR, BOLIVIA Y CHILE}

Los Acuerdos de Traslados de Personas Condenadas entre los Estados Partes del MERCOSUR entre sí y entre éstos con la República de Bolivia y la República de Chile son instrumentos que poseen idéntico contenido y responden -literalmente- a la letra de la Dec. CMC N ${ }^{\circ} 34 / 04$. Además de cumplir en forma real con los compromisos asumidos por los Estados Parte de dar protección y fomento de los derechos humanos en toda la región ${ }^{35}$.

Esta nueva normativa completa los esquemas de cooperación en materia penal ya existentes que unen a los Estados Parte en forma bilateral y simplifica la labor jurisdiccional, generando como pocas veces se ha visto en el MERCOSUR la tan anhelada armonización y asimilación legislativa ${ }^{36}$.

31 Artículo 31.

32 Artículo 38 POP.

33 Característica propia de un esquema supranacional que dota al proceso de mayor dinamismo -entre otras cosas-. Igualmente, debemos lamentar que esta metodología no ha sido utilizada con posterioridad, a excepción de la llamada "supranacionalidad atenuada" empleada para la reorganización del Parlasur respecto de la cantidad de parlamentarios que posee cada Estado Parte. Aunque corresponde señalar que dicha similitud no resulta del todo idéntica en su formulación a la utilizada en las decisiones bajo análisis.

34 Chile incorporó a su legislación interna la decisión en 2012 y Ecuador por adhesión a partir del 30 de junio de 2008.

35 Voluntad que se reflejó expresamente en sus considerandos al sostener que la rehabilitación social del condenado es una finalidad humanitaria.

36 Aunque aún no sea posible referirse a la operatividad de las CMC/Dec. nº14/98 y n¹5/98 que intentan regir las cuestiones atinentes a la extradición en el MERCOSUR.

Máxime cuando ellas, el traslado de condenados a sus países de origen y el Protocolo de San 
La primera nota de interés que puede señalarse es que ya no es necesario remitirse a la ley interna para encontrar un marco regulatorio general que dé respuesta -obviamente parcializada- a los desfasajes existentes entre cada uno de los tratados especiales que unen a los Estados Parte en la materia, así como se diluyen las diferencias de trato que giraban en torno de los criterios de cooperación con los Estados según se aplicara una norma de derecho internacional específica o -ante su ausencia- el principio de reciprocidad.

Las demás notas se desprenden de sus estipulaciones específicas.

Así, se prevé un gran avance mediante la ampliación de las situaciones por las cuales se puede acceder al traslado. Anteriormente sólo se daba curso a los traslados para casos de condenas firmes y ejecutoriadas de privación de libertad ${ }^{37}$. Como consecuencia de esta nueva normativa también se accede a él en casos de condena condicional o libertad condicional, anticipada o vigilada ${ }^{38}$.

En cuanto a la parte faltante de la pena no puede ser inferior a 1 año para su procedencia, salvo acuerdo en contrario ${ }^{39}$.

Se reafirma la necesidad de contar con el consentimiento y conocimiento de las condiciones legales por parte del condenado. Y se agrega la obligación para los Estados Parte de informar sobre el contenido de este Acuerdo a todo ${ }^{40}$ condenado por sus tribunales y la posibilidad de que el Estado receptor verifique que el consentimiento y conocimiento en cada caso particular es tal, a fin de evitar situaciones anómalas que puedan ser -en realidad- expulsiones encubiertas unilaterales por voluntad del Estado sentenciador ${ }^{41}$.

Se recepta un criterio amplio y se acepta que el origen de la petición sea respecto de un nacional o residente legal y permanente del Estado receptor ${ }^{42}$.

Se unifica el criterio en la valoración del delito, correspondiéndole a ambos Estados el análisis en torno a la doble subsunción. No obstante, se establece que no debe atenderse para ello a las diferencias de denominación que puedan tener los delitos en cada Estado, la concordancia debe serlo en la substancia ${ }^{43}$.

Se unifica también el criterio en torno a quién puede solicitar el traslado, facultándose a ambos Estados, al propio condenado o a tercera

Luis -con sus agregados- vendrían a representar desde el ámbito normativo del MERCOSUR lo que la Ley 24.767 representa en el ámbito interno de la República Argentina.

37 Tal como acontecía en Argentina por aplicación de las previsiones de la Ley 24.767 o de los tratados bilaterales y multilaterales.

38 Artículo 2, inciso 1, segundo párrafo.

39 Artículo 3, inciso 6.

40 La negrita es propia.

41 Artículo 3 , inciso 2, artículo 4 y artículo 5, inciso 4.

42 Artículo 2 in fine.

43 Artículo 3, inciso 3. 
persona en su nombre ${ }^{44}$.

La facultad para denegar el traslado recae sobre ambos Estados; aunque dicha decisión debe ser fundada ${ }^{45}$.

La pena continúa cumpliéndose conforme la Ley del Estado receptor y su revisión será facultad exclusiva del sentenciador ${ }^{46}$.

Se mantiene la imposibilidad de investigar o procesar al condenado trasladado por hechos iguales, así como que los gastos del traslado corren por cuenta del Estado sentenciador hasta el momento de la entrega ${ }^{47}$.

Se prevén también dos cláusulas que favorecen su aplicación y agilizan su trámite: la ausencia de necesidad de legalizaciones y la posibilidad de utilización de todo tipo de medios tecnológicos para la remisión de informes y documentación ${ }^{48}$.

\section{LOS DESAFÍOS QUE PLANTEA LA LUCHA CONTRA EL CIBERCRIMEN}

Por su parte, la cuestión de la criminalidad informática viene generando profundos cambios en el ámbito de la asistencia judicial internacional. Por un lado, porque la ubicuidad de los delitos de base tecnológica dejan, muchas veces, perplejas a las jurisdicciones locales por la dificultad en la determinación de nociones que parecerían tan básicas como el lugar de ocurrencia del delito o las normas procedimentales para la obtención de la prueba.

Por el otro, porquela misma lógica de la Sociedad de la Información ha puesto en consideración nuevos actores en la investigación tecnológica de los delitos. Hoy día confluyen en la investigación del delito informático tanto los propios Estados a través de sus órganos judiciales y de seguridad como los actores privados que prestan servicios relacionados con internet y que, por sus características trascienden fronteras y jurisdicciones

En suma, circundando a la asistencia judicial internacional clásica -aquella que ocurre entre Estados Nacionales y/o organismos internacionales- se van sucediendo colaboraciones y entrecruzamiento de información para la investigación criminal provista a los órganos judiciales sin distinción de nacionalidad por parte de las prestadoras de servicios en internet (ESP) y de las prestadoras del servicio de internet (ISP).

Esta virtual asistencia internacional no se rige, como es obvio, por los convenios internacionales, sino que se va construyendo a partir

$\overline{44 \text { Artículo 5, inciso } 1 .}$.

45 Artículo 8, inciso 1, segundo párrafo.

46 Artículo 10, incisos 2, 3 y 4 y artículo 11.

47 Artículo 8, inciso 3 y artículo 10, inciso 1.

48 Artículos 13 y 15. Ambas cláusulas se presentan en consonancia con los términos del artículo 2 inciso k del Protocolo de San Luis. 
de manuales de buenas prácticas, guías de acción para fuerzas de la ley (Law Enforcement Guidelines) propuestas por las compañías de internet a partir de la propia interpretación de las normas locales que las obligan e, incluso, por relaciones interpersonales que generan vínculos de confianza entre las empresas y las instituciones.

En este marco algo caótico y en constante evolución, el papel de los organismos internacionales resulta fundamental ya que son los únicos capaces de generar practicas uniformes que vinculen a los Estados y, principalmente, provean a los particulares de un marco normativo que les dé previsibilidad y los proteja de eventuales consecuencias jurídicas (incluso penales) en las que hoy día pueden recaer por estar lidiando con una infinidad de sistemas jurídicos diferentes ${ }^{49}$.

Quizás el esfuerzo más logrado para conseguir esta armonización se haya alcanzado en el ámbito europeo a partir de la Convención de Budapest ${ }^{50}$ y el protocolo de Lanzarote. Puesto a consideración de los Estados Miembro el 23 de noviembre de 2001 por el Consejo de Europa, este convenio tiene la particularidad de que fue abierto a la firma de cualquier país del mundo ${ }^{51}$.

Y si bien este modelo, inédito, parecería desdibujar el sistema de homogeneización normativa que ejercen los órganos de la Unión Europea, esta opción parece acertada teniendo en cuenta que, como se dijo, el problema de la cibercriminalidad se resiste a ser enmarcada en límites territoriales, aunque sea tan extenso como la misma Europa.

Por otra parte, la Convención de Budapest se enmarca en la práctica usual en estos tiempos en lo que hace a instrumentos bilaterales para la lucha contra algún tipo de criminalidad. En su primera parte establece un glosario de definiciones a utilizar ${ }^{52}$, para luego proponer figuras penales específicas ${ }^{53}$ que, como es común en estos instrumentos, sirven tanto como modelo normativo para los países firmantes como también suplen para la doble subsunción en los supuestos que esta sea exigida por los órdenes nacionales de los Estados ${ }^{54}$.

A continuación, establece mecanismos de colaboración internacional, las pautas tradicionales para la determinación de la jurisdicción de los delitos y, por fin, la base jurídica para la asistencia internacional y la extradición ${ }^{55}$.

Hasta el momento este instrumento es el único en la materia que se encuentra vigente, aunque otros órdenes internacionales como la

49 SCHIFF BERMAN, Paul. "From International Law to Law and Globalization”. Columbia Journal of Transnational Law, 43, p. 485.

50 DÍAZ GÓMEZ, A. "El delito informático, su problemática y la cooperación internacional como paradigma de su solución: El Convenio de Budapest". REDUR 8, 2010, p. 169-203.

51 Artículos 37 y 38 .

52 Capítulo 1.

53 Capítulo 2, sección 1.

54 Artículo 24.

55 Capítulo 1, sección 2, capítulo 1, sección 3 y capítulo 3 respectivamente. 
Organización de los Estados Americanos o la propia Naciones Unidas están realizando ingentes esfuerzos para la elaboración de convenios similares. En las Naciones Unidas, por ejemplo, se aprobó el capítulo relacionado con el cibercrimen en el marco de la Oficina de las Naciones Unidas contra la Droga y el Crimen (UNODC, por sus siglas en inglés), que se encuentra en plena búsqueda de consensos para celebrar un convenio de estas características. Por su parte, la OEA ha generado la Estrategia Interamericana Integral para Combatir las Amenazas a la seguridad cibernética ${ }^{56}$ que ha puesto el tema en agenda en el ámbito interamericano.

\section{EL CIBERCRIMEN Y EL MERCOSUR}

En lo que hace al tema que nos ocupa, esto es el MERCOSUR, si bien no existe un proyecto de elaboración de un instrumento internacional similar, se han planteado interesantes propuestas para la coordinación y cooperación en cuestiones de cibercrimen y ciberseguridad.

Recientemente, en el Comunicado Conjunto de los Presidente de los Estados Parte del MERCOSUR ${ }^{57}$ se destacó la importancia de las Reuniones de Autoridades sobre Privacidad y Seguridad de la Información del MERCOSUR para la proposición de políticas e iniciativas comunes en el área de seguridad cibernética, la privacidad, la protección de los datos personales, la confianza en el uso de Internet, la prevención y el combate al cibercrimen, mediante estrategias y políticas de promoción de la coordinación local y regional respetando las particularidades de los Estados Parte. Esta reunión, denominada RAPRISIT, si bien tiene características más técnicas que jurídicas, viene haciendo importantes contribuciones para la planificación de una estrategia conjunta en materia de seguridad informática y combate contra el cibercrimen.

Sería deseable que este órgano tomara definitivo protagonismo en el análisis de la normativa de los Estados Parte con el objeto de determinar si éstas alcanzan los estándares deseados en materia de protección de datos personales.

Otra vez aquí, el ejemplo de la experiencia europea es encomiable. Mediante la directiva Directiva 95/46/CE se establecieron los presupuestos mínimos para el tratamiento de datos personales, que establece un mínimo común para los países miembros. Además, establece un procedimiento de control para terceros países en el caso de trasmisión de datos fuera del contexto europeo ${ }^{58}$.

56 AG/RES. 2004 (XXXIV-O/04).

57 Suscripta en la Ciudad de Asunción el 21 de diciembre de 2015, en ocasión de la XLIX Reunión Ordinaria del Consejo del Mercado Común.

58 Artículo 25. Principios: 1. Los Estados miembros dispondrán que la transferencia a un país tercero de datos personales que sean objeto de tratamiento o destinados a ser objeto de 
Este procedimiento, conocido comúnmente como de "puerto seguro" (safe harbour) ha demostrado ser un interesante control sobre el tratamiento de los datos personales tanto para adentro como afuera de Europa ${ }^{59}$.

Pero más allá de estas promisorias noticias y si bien, como se dijo, no existe un ámbito ni un instrumento específico para cuestiones relacionadas con la cibercriminalidad, los tratados referidos cuentan con herramientas que pueden responder a las exigencias planteadas en la lucha contra esta problemática.

Más arriba se hizo mención a estos instrumentos y su operatividad dentro del MERCOSUR, por lo que resultaría reiterativo insistir en ello. Sin embargo, en lo que hace a este tipo de delitos donde la velocidad en que ocurren los hechos y la volatibilidad de la prueba exigen respuestas inmediatas y eficaces, si bien los instrumentos de asistencia mutua en asuntos penales del MERCOSUR, como la mayoría de los instrumentos de la materia, no tienen referencias expresas a la prueba digital, la viabilidad de la medida de colaboración puede encuadrarse en la posibilidad de requerir documentos u otros elementos de prueb ${ }^{60}$.

En definitiva, la cuestión de lo que podríamos denominar el "ciberderecho" se encuentra aún en sus primeros albores y los órdenes jurídicos nacionales no alcanzan a generar una legislación comprensiva $\mathrm{y}$ adecuada de estas nuevas realidades ${ }^{61}$. Esto responde básicamente a que, por su naturaleza, las nuevas tecnologías y la Sociedad de la Información exceden la lógica de los Estados, circunscriptos en límites geográficos bien determinados donde pueden -solo dentro de ellos-

tratamiento con posterioridad a su transferencia, únicamente pueda efectuarse cuando, sin perjuicio del cumplimiento de las disposiciones de Derecho nacional adoptadas con arreglo a las demás disposiciones de la presente Directiva, el país tercero de que se trate garantice un nivel de protección adecuado.

2. El carácter adecuado del nivel de protección que ofrece un país tercero se evaluará atendiendo a todas las circunstancias que concurran en una transferencia o en una categoría de transferencias de datos; en particular, se tomará en consideración la naturaleza de los datos, la finalidad y la duración del tratamiento o de los tratamientos previstos, el país de origen y el país de destino final, las normas de Derecho, generales o sectoriales, vigentes en el país tercero de que se trate, así como las normas profesionales y las medidas de seguridad en vigor en dichos países.

3. Los Estados miembros y la Comisión se informarán recíprocamente de los casos en que consideren que un tercer país no garantiza un nivel de protección adecuado con arreglo al apartado 2 .

4. Cuando la Comisión compruebe, con arreglo al procedimiento establecido en el apartado 2 del artículo 31, que un tercer país no garantiza un nivel de protección adecuado con arreglo al apartado 2 del presente artículo, los Estado miembros adoptarán las medidas necesarias para impedir cualquier transferencia de datos personales al tercer país de que se trate.

59 Respecto de la República Argentina, se consideró que "garantiza un nivel adecuado de protección por lo que respecta a los datos personales transferidos desde la Comunidad" mediante la decisión C(2003)1731.

60 Artículo 2 inc. h y artículo 23 del Protocolo de Asistencia Jurídica Mutua en Asuntos Penales del MERCOSUR.

61 SUZOR, Nicolas. "The role of The Rule of Law in Virtual Communities". Berkeley Technology Law Journal, vol 25, 1817. 
imponer sus exigencias jurídicas ${ }^{62}$.

De allí que, como se dijo, las regulaciones internacionales de los fenómenos relacionados con las tecnologías de la información exigen un ámbito más amplio para su aplicación.

\section{CONCLUSIONES}

De lo dicho puede sostenerse que la normativa MERCOSUReña, junto con la generalidad de la normativa internacional, no posee hasta el día de hoy un marco específico para hacer frente a la realidad cada vez más extendida del cibercrimen.

Sin embargo, por un lado, los instrumentos de asistencia judicial mutua en asuntos penales se presentan como herramientas útiles -aun con el acotado alcance que revisten- para paliar esta ausencia.

Se verifica una creciente preocupación en los órganos centrales del MERCOSUR para asumir esta conflictividad y, en ese sentido, anhelamos la generación de un marco normativo adecuado para hacerle frente.

\section{REFERENCIAS BIBLIOGRÁFICAS}

Del CARRIL, Enrique; DELUCA, Santiago. "La Extradición en el Ámbito del MERCOSUR”. Sup. Dcho. Penal.2003, vol 11.

DELUCA, Santiago. "El MERCOSUR necesita su Maastricht”. Revista Pensar en Derecho. 2012. n ${ }^{\circ} 1$.

DELUCA, Santiago. "El MERCOSUR tras la suspensión de Paraguay y el ingreso de Venezuela: ponderación del Laudo TPR No1/2012". Papeles de Derecho Europeo e Integración Regional. 2013, n 16.

DELUCA, Santiago. "Es correcto hablar de un derecho penal del MERCOSUR?". En Derecho Penal Empresario. Buenos Aires: Editorial BdeF, 2010.

DELUCA, Santiago. Unión Europea y MERCOSUR: efectos del Derecho Comunitario en las legislaciones nacionales. Buenos Aires: Editorial Rubinzal Culzoni.

DELUCA, Santiago. Unión Europea y MERCOSUR: los efectos del derecho comunitario sobre las legislaciones nacionales. Buenos Aires: RubinzalCulzoni Editores, 2003.

DÍAZ GÓMEZ, A. "El delito informático, su problemática y la cooperación internacional como paradigma de su solución: El Convenio de Budapest". REDUR 8, 2010, p. 169-203.

DIBUR, José Nicasio; DELUCA, Santiago. Extradiciones: tratados y

62 ZITTRAIN, Jonathan. "Be Careful What You Ask For: Reconciling a Global Internet and Local Law". Harvard Law School Public Law, Research Paper No. 60, <http://ssrn.com/ abstract_id=395300> 
convenios. Buenos Aires: Editorial Ad Hoc, 2006.

FIERRO, Guillermo J. La ley penal y el derecho internacional. $2^{\text {a }}$ ed. Buenos Aires: Editorial Tea, 1997.

FLOREAL GONZÁLEZ, Flavio. "MERCOSUR: un orden jurídico debilitado y dispar. La necesidad de un cambio". En $L L$, año 54, ${ }^{\circ} 61$, p. 2.

JARDEL, Silvina; BARRAZA, A. MERCOSUR: aspectos jurídicos y económicos. Buenos Aires: Ciudad Argentina, 1998.

KLEIN VIEIRA, Luciane. "La reforma de las constituciones de los Estados Partes del MERCOSUR". En LL. 25 de julio de 2012, p. 4-7.

MANGAS MARTÍN, Araceli, LIÑÁN NOGUERAS, Diego J. Instituciones y derecho de la Unión Europea. $2^{a}$ ed. sl: McGraw-Hill, 1999.

PEROTTI, Alejandro. Habilitación constitucional para la integración comunitaria. sl: Fundación Konrad Adenauer, 2004.

SAN MARTINO DE DROMI, María Laura. De la nueva historia del Derecho. A propósito del objeto, método y fuentes del Derecho del MERCOSUR. Buenos Aires: Ciudad Argentina, 1997.

SCHIFF BERMAN, Paul. "From International Law to Law and Globalization". Columbia Journal of Transnational Law, 43, p. 485.

SOLER, Sebastián. Derecho Penal Argentino. Act. por Guillermo J. Fierro. Buenos Aires: Editorial TEA, 1992, tomo I.

SUZOR, Nicolas. "The role of The Rule of Law in Virtual Communities". Berkeley Technology Law Journal, vol 25, 1817.

ZITTRAIN, Jonathan. "Be Careful What You Ask For: Reconciling a Global Internet and Local Law". Harvard Law School Public Law, Research Paper, $n^{\circ}$ 60. Disponible en: <http://ssrn.com/abstract_id=395300>

\section{RESUMEN BIOGRÁFICO}

Santiago Deluca es Abogado y Doctor en Derecho. Especializado en Derecho de la Competencia, Estudios Internacionales, Administración y Gestión de Instituciones Públicas. Profesor universitario. Preside la Asociación de Estudios de Integración -AdEI. Autor de libros y artículos de la especialidad. Secretario del TPR, en el periódo 2008-2011. Desde 2012 ejerce como abogado en comercio internacional, aduanas y arbitrajes. Ejerce la Coordinación Penal de la Superintendencia de Servicios de Salud de la Nación.

Enrique del Carril es Abogado y Magíster en Magistratura y Derecho Judicial. Director del Cuerpo de Investigaciones Judiciales del Ministerio Público Fiscal de Buenos Aires. Profesor grado y posgrado en derecho constitucional, delitos informáticos y nuevas tecnologías. Premio La 
Ley al fortalecimiento del Poder Judicial y Premio del National Center for Missing \& Exploited Children de los EUA por sus aportes a la lucha contra la pornografía infantil en internet. 